\title{
Pengaruh Tipe Kepribadian Big Five Personality dan Self-Compassion terhadap Loneliness pada Remaja dengan Orang Tua Bercerai
}

\section{The Effect of Big Five Personality and Self-compassion on Loneliness in Adolescents with Divorced Parents}

\author{
Irma Rosalinda Lubis, Mauna, Ernita Zakiah, Deni Krisnaputra, \\ Chandra Putri Hafidia Sukmana
}

\begin{abstract}
Fakultas Psikologi, Universitas Negeri Jakarta, Jakarta, Indonesia Email:irma.dik2@gmail.com; mauna@unj.ac.id; ernitazakiah1@gmail.com; denikrisnaputra@gmail.com; chndrptr13@gmail.com
\end{abstract}

KATA KUNCI Kepribadian Big Five, Self-compassion, Loneliness, Remaja dengan Orang Tua Bercerai.

KEYWORDS

Big Five Personality, Self-compassion, Loneliness, Adolescents with Divorced Parents.

ABSTRAK Penelitian ini bertujuan untuk mengetahui pengaruh big five personality dan self-compassion terhadap loneliness pada 125 remaja dengan orang tua bercerai. Penelitian ini menggunakan metode kuantitatif. Alat ukur yang digunakan untuk mengukur loneliness adalah De Jong Gierveld Loneliness Scale (DJGLS). Kepribadian big five diukur dengan Big Five Inventory (BFI) dan alat ukur yang digunakan untuk mengukur self-compassion adalah skala self-compassion oleh Neff. Pengolahan data menggunakan analisis regresi dengan dua prediktor. Hasil pengaruh big five terhadap loneliness diikuti OCEAN adalah $5,2 \%, 3,1 \%, 18,6 \%, 7 \%$ dan $26,1 \%$ dan pengaruh negatif selfcompassion terhadap loneliness pada remaja dengan orang tua bercerai sebesar 5,7\%. Dengan demikian, kecenderungan tertinggi loneliness berada pada anak dengan karakter neurotism dan rendah ditemukan oleh anak yang memiliki selfcompassion tinggi. 
ABSTRACT This study aims to determine the effect of the big five personality and self-compassion towards loneliness in adolescents with devorced parents. This research uses quantitative methods.The measuring instrument used to measure loneliness is De Jong Gierveld Loneliness Scale (DJGLS). The big five personality is measured by Big Five Inventory (BFI) and the measuring instrument used to measure self-compassion is Self-Compassion scale by Neff. Data was processed using reggresion analyze with three predictor. Data processing using regression analysis with two predictors. The results of the big five influence on loneliness followed by OCEAN are $5.2 \%, 3.1 \%, 18.6 \%, 7 \%$ and $26.1 \%$ and the negative effect of self-compassion on loneliness in adolescents with divorced parents is $5.7 \%$. . Thus, the highest tendency of loneliness is found in children with neurotic character and the lowest is found by children who have high self-compassion.

\section{PENDAHULUAN}

Dalam beberapa tahun terakhir, fenomena perceraian mengalami peningkatan. Berdasarkan data yang di unggah oleh Badan Peradilan Agama, pada tahun 2018 terdapat 419.286 pasangan yang bercerai, dimana 307.788 perempuan dan 111.490 pria

Peristiwa perceraian dalam keluarga senantiasa membawa dampak yang mendalam. Kasus ini menimbulkan stres, perubahan fisik, dan mental. Keadaan ini dialami oleh semua anggota keluarga, yakni ayah, ibu, dan anak (Ramdhani dan Krisnani, 2019). Perceraian menjadi beban yang mendalam bagi anak, terlebih lagi ketika anak menginjak usia remaja (Mone, 2019).

Masa remaja adalah masa transisi dari anak-anak menuju dewasa.Masa ini dimulai pada usia 10 hingga 12 tahun dan berakhir pada usia 18 hingga 21 tahun. Selain perkembangan fisik pada masa remaja terdapat pula perkembangan emosi yang dialami (King, 2010). Secara psikologis, emosi manusia terbagi menjadi dua jenis yakni emosi positif (seperti bahagia, gembira, semangat, serta sejenisnya) dan emosi negatif (perasaan tidak menyenangkan seperti sedih, menangis, dan lainya) (Gohm dan Clore, 2000). Remaja yang berasal dari keluarga bercerai memiliki beberapa aspek emosi negatif seperti kurang percaya diri, mood swing, dan traumatis. Beberapa penelitian menunjukan bahwa anak remaja dengan orang tua yang bercerai jauh lebih mungkin mengalami masalah emosi negatif seperti loneliness (Yuliawati dkk., 2007). Selain loneliness, emosi negatif yang mungkin dirasakan oleh remaja dengan orang tua bercerai adalah perasaan marah, merasa tidak aman, terluka dan bingung Sejalan dengan penelitian tersebut, penelitian lain yang dilakukan oleh Hidayati (2018) mengatakan bahwa salah satu resiko yang timbul dari perceraian yang dialami oleh remaja adalah loneliness. Gejolak emosi yang tidak stabil dapat membuat remaja cenderung menjadi sensitif atas situasi yang sedang dialami, karenanya perceraian akan sangat mudah membuat remaja mengalami loneliness. Hal ini dipertegas dengan penelitian Aminah dkk. (2014) yang menyatakan bahwa remaja dengan orang tua yang bercerai sangat sering ditemui dengan tingkat loneliness yang tinggi.

Bruno (2002) memaparkan loneliness merupakan keadaan mental dan emosional yang utamanya dicirikan adanya perasaan-perasaan terasing atau kurangnya hubungan yang bermakna 
dengan individu lain. Individu yang merasakan keadaan tersebut merasa bahwa dirinya tidak diinginkan oleh orang lain atau merasa tidak ada yang mengerti apa yang individu tersebut rasakan. Rasa sedih biasanya menyelimuti hati individu yang sedang merasakan loneliness. Selain itu, Baron (2005) mendefinisikan loneliness sebagai reaksi emosional dan juga reaksi kognitif terhadap dimilikinya hubungan yang lebih sedikit dan tidak memuaskan daripada yang diinginkan oleh orang yang bersangkutan tersebut. Loneliness yang dirasakan oleh individu berpengaruh pada emosi dan pikiran individu. Hal ini menyebabkan individu menerima emosi yang tidak terlalu baik dari luar. Selain itu, loneliness dapat menyebabkan harga diri rendah; dengan begitu, remaja akan kurang percaya diri sehingga akan menutup diri dari lingkungan sosialnya. Penelitian lain mengatakan bahwa loneliness pada remaja dapat membuat remaja cenderung untuk melakukan tindakan melukai diri sendiri (Lubis dan Yudhaningrum, 2020).

Dikutip dari berita CNN Indonesia (2015), loneliness sama bahayanya dengan merokok. Loneliness yang akut dapat meningkatkan resiko mati muda sebesar $14 \%$. Pada kenyataannya tidak semua remaja mengalami dampak kesepian yang sama satu sama lainya. Hal ini dapat disebabkan adanya perbedaan karakteristik yang dimiliki setiap individu. Perbedaan karakteristik ini disebut dengan tipe kepribadian (Dominika, 2018). Hal ini berlaku pada setiap remaja, bukan hanya remaja dengan latar belakang orang tua bercerai. Hal ini sejalan dengan penelitian Neto (2016) yang mengatakan bahwa kepribadian merupakan salah satu faktor yang dapat mempengaruhi loneliness pada masa remaja. Individu yang merasa loneliness cenderung mengembangkan hipersensitivitas terhadap informasi sosial yang negatif, untuk menilai interaksi sosial mereka lebih negatif, dan untuk terlibat dalam perilaku yang lebih defensif.
Kepribadian adalah pola sifat (watak) dan sebuah karakter unik yang memberikan konsisten sekaligus individualitas bagi perilaku seseorang. Kepribadian sebagai pola yang khas dari pikiran, perasaan dan tingkah laku yang membedakan orang yang satu dengan yang lain dan tidak berubah lintas waktu dan situasi (Feist \& Feist, 2008). Kepribadian juga menjadi karateristik yang khas dan menetap serta digunakan untuk berinteraksi dengan lingkungannya. Kepribadian merupakan cara dimana individu bereaksi dan berinteraksi dengan individu lain serta tehadap suatu situasi (Robbins \& Judge, 2008).

Penelitian Kreuger dan Eaton (2010) menyebutkan big five personality merupakan salah satu ciri kepribadian yang penting dan dianggap luas oleh beberapa penelitian termasuk dapat menghindari bias budaya. Hal ini diperjelas dengan penelitian Rammstedt dkk. (2010) yang menyatakan bahwa big five personality dapat menjadi salah satu tipe kepribadian yang baik karena model ini adalah model yang paling diterima dan menonjol untuk mengukur tipe kepribadian dimanapun.

Five factor model, istilah lain untuk big five personality, dianggap menggabungkan berbagai macam perspektif yang berbeda terhadap kepribadian (Keldal \& Atli, 2016). Faktor-faktor yang termasuk dalam teori ini adalah OCEAN (Openess to experience, Conscientiousness, Extraversion, Agreebleness, Neurotism) (Keldal \& Atli, 2016).

Sejumlah penelitian menyebutkan terdapat hubungan antara big five personality dan loneliness. Temuan penelitian sebelumnya mengatakan terdapat hubungan negatif antara opennes to experience dan loneliness (Vanhals, dkk., 2012). Selain itu, ditemukan pula korelasi positif antara conscientiousness dan loneliness (Teppers dkk., 2013). Kemudian, ditemukan pula hasil secara konstan bahwa adanya hubungan antara extraversion dan loneliness (Keldal \& Atli, 2016).Temuan penelitian lain 
menunjukkan karakteristik agreeableness berkorelasi negatif terhadap loneliness (Keldal \& Atli, 2016). Kemudian, terdapat studi yang menunjukkan hubungan yang positif antara neuroticism dan loneliness (Buecker, 2019).

Seseorang dengan karakteristik neuroticism sangat peka terhadap penolakan sosial dan rentan terhadap stres (Buecker, 2019). Loneliness dapat dikurangi dengan berbagai macam cara yang dilakukan oleh individu seperti merubah emosi negatif atau sudut pandang terhadap suatu masalah ke dalam perspektif yang lebih positif. Salah satunya dengan mengasihi diri sendiri merupakan cara yang dapat dilakukan individu agar terbebas dari perasan negatif termasuk loneliness. Konsep mengasihi diri sendiri disebut juga sebagai self-compassion. Menurut Germer (dalam Hidayati \& Maharani, 2013), self-compassion adalah kesediaan diri untuk terbuka dan tersentuh kesadarannya saat mengalami penderitaan dan tidak menghindari atau menolak penderitaan tersebut. Menurut Neff dkk. (2005), self-compassion berfungsi sebagai strategi adaptif bagi pengorganisasian emosi melalui pengurangan emosi negatif dan menciptakan emosi positif berupa kebaikan. Self-compassion tidak hanya berfokus pada penyelesaian emosi yang dapat menjadikan individu lupa dengan masalah yang sedang dihadapi, namun juga berhubungan dengan pengambilan inisiatif untuk merubah dirinya kearah yang lebih positif (Neff \& Kirkpatrick, 2007). Urgensi dari kepentingan menetapkan big five personality dan self compassion sebagai prediktor terhadap loneliness sendiri adalah karena kedua variabel tersebut memiliki korelasi yang tinggi terhadap loneliness (Buecker, 2019). Dengan demikian, penelitian ini ingin mengetahui seberapa besar pengaruh faktor kepribadian big five dan self compassion terhadap loneliness, khususnya pada remaja dengan orang tua bercerai.

\section{METODE PENELITIAN Partisipan}

Populasi yang digunakan dalam penelitian ini adalah remaja yang orang tuanya telah bercerai, yang merupakan warga negara Indonesia, dan berumur 1521 tahun. Partisipan didapatkan melalui media sosial seperti Instagram, Twitter, dan broadcast melalui internet. Terdapat 125 partisipan dalam penelitian ini.Teknik pengambilan sampel pada penelitian ini adalah non-probability sampling, yaitu teknik pengambilan sampel dimana tidak setiap responden memiliki kesempatan yang sama untuk dipilih menjadi karakteristik sampling (Sugiyono, 2016). Secara spesifik, teknik sampling yang digunakan adalah purposive sampling.

\section{Instrumen}

Teknik pengumpulan data yang digunakan dalam penelitian ini adalah angket atau kuesioner. Peneliti menggunakan De Jong Gierveld Loneliness Scale (DJGLS) untuk mengukur kesepian. Instrumen DJGLS terdiri dari 11 item yang terdiri dari lima item favorable dan lima item unfavorable. Instrumen DJGLS memiliki tiga pilihan jawaban yaitu ya (nilai tiga poin), kadangkadang (nilai dua poin), dan tidak (nilai satu poin). Uji coba istrumen dilakukan pada 60 remaja yang orang tuanya bercerai, yang tinggal di berbagai daerah di Indonesia, melalui google form. Diperoleh koefisien reliabilitas Cronbach alpha sebesar 0,828, yang mana menurut kategori Golberg (1981) tergolong reliabel. Sementara itu koefisien corrected item total correlation yang dihasilkan adalah > 0,3 atau mampu mengukur apa yang seharusnya diukur (Rangkuti \& Wahyuni, 2017).

Untuk mengukur big five personality digunakan Big Five Inventory (BFI) yang terdiri dari 44 item, yaitu 31 item favorable dan 17 item unfavorable. Instrumen BFI terdiri dari lima pilihan jawaban, yakni sangat tidak setuju (STS), agak tidak setuju (ATS), netral (N), setuju (S) dan sangat setuju (SS). Uji coba BFI 
pada 60 partisipan menghasilkan koefisien reliabilitas Cronbach alpha sebesar 0,696.

Selanjutnya, untuk mengukur self compassion peneliti menggunakan SelfCompassion Scale, yang terdiri dari 26 item. Akan tetapi, peneliti memodifikasi item menjadi 28 item dengan tiga komponen dasar yaitu self-kindness versus self-judgment, common humanity versus isolation, dan mindfulness versus over-identification. Self-Compassion Scale memiliki lima pilihan jawaban untuk setiap pernyataan, yaitu tidak pernah (nilai satu poin), jarang (nilai dua poin), kadang-kadang (nilai tiga poin), sering (nilai empat poin) dan selalu (nilai lima poin). Koefisien reliabilitas Cronbach alpha alat ukur ini sebesar 0,710 . Kemudian, terdapat sejumlah item Self-Compassion Scale yang memiliki nilai corrected item total correlation $<0,3$ yaitu item nomer 3, 5, 7, 14, 21, 22, 23, dan 25. Dengan nilai di bawah 0,3 tersebut, maka item-item tersebut gugur (Rangkuti \& Wahyuni, 2017). Untuk instrumen Self Compassion Scale sendiri terdapat beberapa data item yang gugur item berada di bawah nilai 0,3 (Rangkuti \& Wahyuni, 2017). Beberapa nomer item yang gugur antara lain 3, 5, 7, 14, 21, 22, 23 , dan 25.

\section{Teknik Analisis Data}

Hipotesis dalam penelitian ini akan dianalisis melalui uji regresi linear, menggunakan program SPSS 25 for windows.

\section{ANALISIS DAN HASIL \\ Uji Normalitas}

Peneliti melakukan uji normalitas antara variabel big five personality maupun self-compassion terhadap loneliness menggunakan teori normal asimtotik. Berdasarkan teori normal asimtotik, apabila $N$ yang lebih besar dari 30, maka distribusi sampling dari mean akan mendekati distribusi normal. Hal tersebut terjadi karena kasus khusus Central Limit Theorem (CLT) yang merupakan bagian teori probabilitas lanjut. Berdasarkan CLT, tingkat akurasi akan semakin baik apabila nilai $N$ semakin besar (Spiegel \&Stephens, 2007). Dalam penelitian ini sampel yang digunakan sebanyak 125 responden yang berarti sudah lebih dari 30 responden sehingga dapat diasumsikan data pada penelitian ini berdistribusi normal.

\section{Uji Linearitas}

Peneliti melakukan uji linearitas dengan pada variabel-variabel yang diteliti. Berdasarkan data Tabel 1, diperoleh nilai signifikasi linearity untuk dimensi-dimensi big five personality (OCEAN) dan loneliness lebih kecil dari 0,05. Artinya, terdapat hubungan yang linear. Kemudian, diketahui hasil analisis hubungan antara variabel self-compassion terhadap loneliness dengan nilai signifikasi deviation from linearity 0,556 lebih besar dari taraf signifikansi $(\alpha=0,05)$, maka hubungan antar variabel dapat dikatakan linear. 
Tabel 1.

Uji Asumsi Linearitas Big Five Personality

\begin{tabular}{llc}
\hline Variabel & \multicolumn{1}{c}{ Dimensi } & Sig. (p-value) \\
\hline & Opennes to experience & 0,011 \\
& Conscientiousness & 0,049 \\
$\begin{array}{l}\text { Tipe Kepribadian } \\
\text { Big Five terhadap }\end{array}$ & Extraversion & 0,000 \\
& Agreeableness & 0,003 \\
& Neuroticism & 0,000 \\
\hline
\end{tabular}

\section{Kategorisasi Skor Variabel}

Loneliness

Penentuan kategorisasi norma ini berdasarkan teori asli dari De Jong Girveld yang membagi tingkat kesepian menjadi empat kategori yakni sangat parah (skor 11) parah (skor 9-10) sedang (skor3-8) dan untuk mengkategorisasikan skor loneliness ini, peneliti menggunakan hasil mean dari perhitungan SPSS versi 25. Dapat disimpulkan, partisipan penelitian ini memiliki perasaan loneliness di tingkat sedang, parah dan sangat parah. Kategorisasi skor dilakukan untuk melihat letak skor responden dengan skor responden lainnya.

Tabel 2

Kategorisasi Skor Loneliness

\begin{tabular}{lcc}
\hline \multicolumn{1}{c}{ Kategori Skor Loneliness } & Frekuensi & Persentase \\
\hline \hline Sangat Parah & 24 & $19,2 \%$ \\
Parah & 42 & $33,6 \%$ \\
Sedang & 52 & $41,6 \%$ \\
Tidak Kesepian & 7 & $5,6 \%$ \\
\hline \hline Total & 125 & $100 \%$ \\
\hline
\end{tabular}


Self Compassion

Kategorisasi self-compassion terbagi menjadi dua, yaitu kategori skor tinggi dan rendah. Mengkategorisasikan skor self- compassion ini, penulis menggunakan hasil mean dari perhitungan SPSS versi 25 . Berikut tabel mengenai kategori variabel self-compassion.

Tabel 3

Kategorisasi Skor Self-Compassion

\begin{tabular}{ccc}
\hline Keterangan & Skor & Frekuensi \\
\hline Rendah & $\mathrm{X}<70,18$ & 61 \\
Tinggi & $\mathrm{X}>70,18$ & 64 \\
\hline Total & & 125 \\
\hline $\begin{array}{c}\text { Rendah, jika } \quad: \mathrm{X}<\text { Mean } \\
\text { Tinggi, jika }: \mathrm{X}>\text { Mean }\end{array}$ & &
\end{tabular}

Berdasarkan Tabel 3 diatas, diketahui bahwa partisipan dengan self compassion yang rendah sebanyak 61 orang dan partisipan dengan selfcompassion yang tinggi sebanyak 64 orang.

\section{Big Five Personality}

Kategorisasi skor dilakukan untuk melihat letak skor partisipan dengan skor partisipan lainya. Kategori bisa saja dilakukan dalam dua kategori yakni tinggi atau rendah dan bisa masuk ke dalam tiga kategori seperti tinggi, sedang dan rendah (Rangkuti dan Wahyuni, 2017). Dalam penelitian ini, skor variabel Big Five Personality dikategorikan sebagai rendah dan tinggi berdasarkan teori pengkategorisasian Rangkuti dan Wahyuni (2012). Tabel 4 menyajikan kategorisasi skor dimensi-dimensi variabel Big Five Personality.

Tabel 4

Kategorisasi Skor Big Five Personality

\begin{tabular}{lccc}
\hline \multicolumn{1}{c}{ Dimensi } & Kategorisasi & Frekuensi & Persentase \\
\hline Opennes to & Rendah & 10 & $8.0 \%$ \\
experience & Tinggi & 115 & $92.0 \%$ \\
Conscientiousness & Rendah & 65 & $52.0 \%$ \\
& Tinggi & 60 & $48.0 \%$ \\
Extraversion & Rendah & 45 & $36.0 \%$ \\
& Tinggi & 60 & $64.0 \%$ \\
Agreeableness & Rendah & 6 & $4.8 \%$ \\
\multirow{2}{*}{ Neuroticism } & Tinggi & 119 & $95.2 \%$ \\
& Rendah & 27 & $21.6 \%$ \\
\hline
\end{tabular}


Uji Hipotesis: Analisis Regresi Big Five Personality dan Self Compassion terhadap Loneliness

Berdasarkan data yang tersaji pada Tabel 5, diketahui bahwa self compassion berpengaruh secara signifikan terhadap loneliness pada remaja dengan orang tua yang bercerai $(\mathrm{F}=7,501 ; \mathrm{p}=0,007)$. Semakin tinggi self-compassion maka semakin rendah loneliness pada remaja dengan orang tua bercerai, serta peningkatan self-compassion akan mempengaruhi penurunan loneliness juga. Begitu juga sebaliknya, semakin rendah self-compassion maka semakin tinggi pula loneliness. Besaran kontribusi self compassion terhadap loneliness dalam penelitian ini sebesar $5,7 \%$. Sementara itu, loneliness juga dipengaruhi oleh variabel lain yang tidak diteliti dalam penelitian ini sebesar 94,3\%.

Berdasarkan data yang tersaji pada Tabel 6, diketahui bahwa dimensidimensi big five personality berpengaruh secara signifikan terhadap loneliness pada remaja dengan orang tua yang bercerai $(\mathrm{F}=3,962-43,501 ; \quad \mathrm{p}=0,031-0,261)$. Besaran kontribusi dimensi-dimensi big five personality terhadap loneliness dalam penelitian ini sebesar $3,1 \%$ hingga $26,1 \%$.

Tabel 5

Analisis Regresi Big Five Personality dan Self-Compassion terhadap Lonelines

\begin{tabular}{cccc}
\hline Variabel & $\mathrm{p}$ & Fhitung & $\mathrm{R}^{2}$ \\
\hline $\begin{array}{c}\text { Openness to } \\
\text { experience }\end{array}$ & 0,011 & 6,736 & 0,052 \\
$\begin{array}{c}\text { Conscientiousness } \\
\text { Extraversion }\end{array}$ & 0,049 & 3,962 & 0,031 \\
Agreeableness & 0,000 & 28,147 & 0,186 \\
Neuroticism & 0,000 & 43,501 & 0,261 \\
Self-Compassion & 0,007 & 7,501 & 0,057 \\
\hline
\end{tabular}

\section{DISKUSI}

Hasil penelitian ini menunjukan terdapat pengaruh signifikan antara big five personality terhadap loneliness sebesar $(\mathrm{F}=3,962-43,501 ; \mathrm{p}=0,031$ 0,261). Besaran kontribusi dimensidimensi big five personality terhadap loneliness dalam penelitian ini sebesar $3,1 \%$ hingga $26,1 \%$, dimana sumbangan terbesar diberikan oleh dimensi neuroticism, besar diberikan oleh dimensi neuroticism, yakni sebesar $26 \%$. Hal ini sesuai dengan penelitian sebelumnya Abdellaoui dkk. (2012) yang menyatakan bahwa neuroticsm memiliki nilai prediktor yang paling tinggi dibandingkan dengan dimensi lain pada big five personality. Sejalan dengan itu, teori mengatakan bahwa neurotism sangat peka terhadap penolakan sosial dan rentan terhadap stres (Vanhalst dkk., 2012).

Hasil penelitian ini juga menunjukan 
adanya pengaruh negatif self-compassion terhadap loneliness pada remaja dengan orang tua bercerai dengan $(\mathrm{F}=7,501$; $\mathrm{p}=0,007)$ dan kontribusi dimensinya sebesar $5,7 \%$. Hal ini sesuai dengan penelitian Neff dkk. (2005), selfcompassion berfungsi sebagai strategi adaptif bagi pengorganisasian emosi melalui pengurangan emosi negatif dan menciptakan emosi positif berupa kebaikan. Selain itu, self-compassion merupakan salah satu bahasan mengapa seseorang mampu bertahan, memahami, dan menyadari makna suatu kesulitan ke dalam hal yang positif (Diana, 2015). Self-compassion tidak hanya berfokus pada penyelesaian emosi yang dapat menjadikan individu lupa dengan masalah yang sedang dihadapi, akan tetapi selfcompassion berhubungan dengan pengambilan inisiatif untuk merubah dirinya kearah yang lebih positif (Neff \& Kirkpatrick 2007).

Temuan ini juga didasarkan pada keterbatasan dalam penelitian yakni jumlah partisipan yang didapatkan belum mewakili seluruh daerah di Indonesia. Walaupun begitu, kondisi ini tidak mengurangi kredibilitas dari temuan hasil penelitian.

\section{SIMPULAN}

Berdasarkan pengujian statistik dapat disimpulkan bahwa terdapat pengaruh yang signifikan antara tipe kepribadian big five personality dan self compassion terhadap loneliness pada remaja dengan orang tua bercerai. Hal ini membuktikan bahwa karakteristik kepribadian atau tipologi kepribadian sangat berperan penting terhadap munculnya loneliness. Kemudian, proses mengasihi diri sendiri juga dibutuhkan agar mampu mengurangi loneliness pada remaja dengan orang tua yang bercerai nantinya, karena semakin tinggi self compassion maka akan semakin rendah tingkat loneliness yang dirasakan. Berdasarkan hal tersebut kecenderungan tertinggi loneliness dapat dimiliki oleh partisipan dengan karakter neurotism. Sementara, kecenderungan loneliness yangendah dapat dimiliki oleh partisipan dengan self-compassion yang tinggi.

\section{SARAN}

Penelitian ini memiliki keterbasan seperti tidak tersebarnya responden secara merata di seluruh Indonesia sehingga peneliti selanjutnya diharapkan dapat menyempurnakan penelitian ini terutama terkait dengan responden yang diteliti. Diharapkan untuk penyebaran sampel dilakukan secara merata, tidak dominan pada suatu wilayah tertentu, atau tidak dominan pada jenis kelamin tertentu hal ini bertujuan agar data yang didapatkan bersifat bervariasi dan lebih menarik.

Melalui penelitian ini, diharapkan para remaja yang memiliki orangtua bercerai dapat memandang kejadian perceraian kedua orangtuanya dengan rasa penuh optimisme karena tidak semua anak dengan orang tua bercerai memiliki dampak yang negatif. Dari hasil penelitian ini kita bisa melihat bahwa berpikir positif dan mengembangkan kebaikan dan kasih kita terhadap sesama akan mengurangi emosi negatif akibat perceraian.Setiap kepribadian memiliki respon yang berbeda-beda akibat situasi percerain ini, namun tidak menutup kemungkinan semua tipe kepribadian mampu bangkit dan lebih optimis kedepannya. 


\section{DAFTAR PUSTAKA}

Abdellaoui, A., Chen H.Y., Willemsen, G., Ehli, E.A., Davies, G.E., Verweij, K.J.H., Nivard, M.G., de Geus, E.J.C., Boomsma, D.I., Cacioppo, J.T. (2019). Associations between loneliness and personality are mostly driven by a genetic association with neuroticism. Journal of Personality, 87(2), 386397. doi: 10.1111/jopy.12397.

Aminah., Andayani, T.R., \& Karyanta, N.A. (2014). Proses penerimaan anak (remaja akhir) terhadap perceraian orang tua dan konsekuensi psikososial yang menyertainya. Journal of Health Education, 1(1). 1-11.

Baron, R. (2005). Psikologi sosial. Erlangga.

Bruno, F. J. (2002). Conguer loneliness, menaklukan kesepian. Gramedia Pustaka Utama.

Buecker, S., Maes, M., Denissen, J. J. A., \& Luhmann, M. (2020). Loneliness and the big five personality traits: A meta- analysis. European Journal of Personality, 34(1), 8-28. doi: 10.1002/per.2229.

De Jong Gierveld J., Van Tilburg T. G., \& Dykstra, P. A. (2006). Loneliness and social isolation. In D. Perlman \& A. Vangelisti (Eds.), The Cambridge handbook of personal relationship (pp.485-

500).Cambridge University Press.

De Jong Gieveld, J., van Tilburg, T. G., \& Dykstra, P. A. (2006). Loneliness and social isolation. Cambridge University Press.

Dominika., \& Virlia, S. (2018). Hubungan tipe kepribadian ekstrovert-introvert dengan penerimaan sosial pada siswa. Konselor, 7(1), 31-39. doi:
10.24036/02018718735-0-00.

Feist, J., \& Gregory J. Feist. (2008). Theories of personality (edisi 6.). Pustaka Pelajar.

Gohm, C. L., \& Clore, G.L. (2000). Individual differences in emotional experience mapping available scale to process. Personality and Social Psychology Bulletin, 26(6), 679679.

Hidayati, D. S. (2018). Family functioning dan loneliness pada remaja dengan orang tua tunggal. Jurnal Ilmiah Psikologi Terapan, 6(1). 54-62. doi:10.22219/per.5432.

Keldal, G., \& Atli, A. (2016). University students personality traits as predictor of their loneliness level. Cukurova Universitesi Egitim Fakultesi Dergisi, 45(2), 131-134.

King, L. (2010). Psikologi umum. Salemba Humanika.

Lubis, I. R., \& Yudhaningrum, L. (2020). Gambaran kesepian pada remaja pelaku self-harm. Jurnal Penelitian dan Pengukuran Psikologi, 9(1), 1421.

DOI: https://doi.org/10.21009/JPPP.091. 03.

Neff, K., Hsieh, Y., \& Dejitterat, K. (2005). (2005). Self-compassion, achievement goals, and coping with academic failure. Self and Identity, 4, 263-287.

Neff, K.D., Kirkpatrick, K. L., \& Rude, S. S. (2007). Self compassion and adaptive psychological functioning. Journal of Research in Personality, 41, 139-154.

Ramdhani, N., \& Krisnani (2012). Adaptasi bahasa dan budaya inventori big five. Jurnal Psikologi, 39(2), 189207. 
Rangkuti, A., \& Wahyuni (2012). Konsep dan teknik analisis data penelitian kuantitatif bidang psikologi dan pendidikan. FIP Press.

Safitri, A. M. (2017). Proses dan faktor yang mempengaruhi perilaku memaafkan pada remaja broken home. Jurnal Ilmiah Psikologi, 5(1), 34-40.

Srisusanti, S., \& Zulkaida. (2013). Studi deskriftif mengenai faktor-faktor yang mempengaruhi kepuasan perkawinan pada istri. Universitas Gunadarma, 7(6), 8-12.

Sugiyono. (2016). Metode penelitian kuantitatif, kuantitatif dan $r \& d$. Alfabeta.

Teppers, E., Klimstra, T. A., van Damme,
C., Luyckx, K., Vanhalst, J., \& Goossens, L. (2013). Personality traits, loneliness and attitudes towards alonessin adolescence. Journal of Social and Personal Relationships, 30(8), 1045-1063. doi: 10.1177/0265407513481445.

Vanhalst, J., Klimstra, T. A., Luyckx, K., Scholte, R. H. J., Engels, R. C. M. E., Goossens, L. (2012). Interplay of loneliness of depressive symptoms across adolescence: Exploring the role of personality. $J$ Youth Adolesc, 41(6), 776-787. doi: 10.1007./s10964-011-9726-7.

Yuliawati, L. S. (2006). Perubahan pada remaja tanpa ayah. Arkhe, 12(1), 919. 